\title{
PROCESSO DE COMUNICAÇÃO NO AMBIENTE INTERNO DE UMA INDÚSTRIA: COMPREENSÕES A PARTIR DA ANÁLISE DE CONTEÚDO
}

\author{
PROCESO DE COMUNICACIÓN EN EL AMBIENTE \\ INTERNO DE UNA INDUSTRIA: COMPRENSIONES \\ A PARTIR DEL ANÁLISIS DE CONTENIDO
}

Marcio Ferreira da Silva*

\begin{abstract}
RESUMO
Introdução: O presente trabalho discute e analisa o processo de comunicação em uma indústria do setor sucroalcooleiro do estado de São Paulo. Visa identificar a compreensão e participação dos agentes mediadores da informação no processo de comunicação.

Metodologia: A pesquisa se apresenta como um estudo de caso. O corpus analisado foi composto por oito entrevistas realizadas em 2013 em uma das 20 maiores indústrias produtoras de álcool em 2010 no estado de São Paulo. Quanto à análise das entrevistas foi utilizada a Análise de Conteúdo.

Resultados: Verificou-se alguns ruídos e problemas quanto ao uso de meios no processo. A participação dos agentes é identificada como fundamental ao fluxo de informação e comunicação formal e informal do ambiente interno da indústria.

Conclusões: Contudo, sugere um olhar mais efetivo sobre os ruídos e barreiras de acesso à informação e suas consequências à indústria. Por fim, se reconhece a ação dos agentes mediadores da informação ou gatekeepers entre os respondentes dos departamentos analisados.
\end{abstract}

Palavras-chave: Comunicação da informação. Agentes mediadores. Indústria sucroalcooleira - São Paulo. Análise de conteúdo.

\section{INTRODUÇÃO}

A informação constitui-se como princípio basilar nas atividades das organizações. É valorizada pela sua circulação interna e externa à * Doutorando em Ciência da Informação pela Universidade Estadual Paulista Júlio de Mesquita Filho (UNESP/Marília). Bibliotecário na Universidade Federal de Alagoas (UFAL) E-mail: soimers@gmail.com

$$
\text { Inf. Inf., Londrina, v. 21, n. 1, p. } 306 \text { - 323, jan./abr. } 2016 .
$$


tomada de decisões. Determinante para as indústrias em cenários amplamente competitivos, em especial, para aquelas do setor produtor de etanol com base na cana-de-açúcar.

Nota-se, no contexto histórico, estreita relação entre a história do Brasil e a do setor sucroalcooleiro na composição do parque fabril nacional. Na implantação da lavoura canavieira, na constituição do setor no Estado de São Paulo e no Brasil (BRAY; FERREIRA; RUAS, 2000; FURTADO, 2005; MAIA, 2010; PETRONE, 1968).

A comunicação na indústria visa aproximar as informações consideradas essenciais ao desempenho das atividades de qualquer indivíduo. Mensagens entre emissores e receptores, viabilizados por meios ou canais compartilhados à transferência de informação (EJARQUE, 2000; MARTíNEZ SOUSA, 2004). Desvenda-se como parte da prática social, a partir de negociações e convenções, constituídas da rotina de significação e (re)significação do cotidiano.

Dessas relações, emergem processos interpretativos da realidade, registrados e retroalimentados em processos contínuos de produção e compartilhamento de informação. A comunicação da informação é compreendida como um processo que promove a interação e a troca de informações entre os envolvidos nos processos produtivos da indústria.

Diante do exposto, o presente trabalho apresenta breves reflexões acerca dos fluxos da informação no ambiente interno de uma indústria. Precisamente, se buscou analisar os processos internos de comunicação e a participação dos agentes mediadores da informação em uma indústria produtora de etanol no Estado de São Paulo. Os dados analisados nesta comunicação fazem parte das entrevistas da pesquisa de mestrado do autor defendida no ano de 2013, e financiada pelo Conselho Nacional de Desenvolvimento Científico e Tecnológico, e pela Fundação de Amparo à Pesquisa do Estado de São Paulo.

A coleta foi realizada em três departamentos de uma indústria entre os meses de março e abril de 2013, a saber: Departamento de 
Controle de Qualidade, Departamento de Recursos Humanos e Departamento de Segurança do Trabalho.

\section{COMUNICAÇÃO INTERNA E AGENTES MEDIADORES}

Nota-se que a Ciência da Informação busca, incessantemente, compreender as dimensões fenomenológicas da produção de informação, uma vez que existem perspectivas à busca de tal compreensão. Envolve inúmeras implicações teóricas, conceituais e metodológicas que, por sua vez, edificam a informação enquanto objeto de análise e acolhimento de suas complexidades como "[...] os princípios e práticas da criação, organização e distribuição da informação desde sua criação até sua utilização, e sua transferência ao receptor em uma variedade de formas, por meio de uma variedade de canais." (SMIT; BARRETO, 2002, p. 17-18).

Essa atividade torna-se ainda mais grandiosa, quando se leva em consideração a elevada produção de informação que se estabelece socialmente. Nesse contexto, ações fundem-se em esforços comuns entre disciplinas como Administração, Filosofia, Ciências Humanas, dentre outras. No que tange às negociações a outros campos do saber, exigem-se aproximações teóricas, conceituais e dialógicas em foco, já que a relação da comunicação enquanto processo e a informação enquanto fenômeno é indissociável, dadas suas complexidades e inúmeras definições para ambas em vários contextos dos quais a primeira trata do compartilhamento da segunda (SARACEVIC, 1999).

Diversos olhares se debruçaram sobre a comunicação com o objetivo de elaborar metodologias para explicar o processo de comunicação. Algumas caminharam em paralelo a um ambiente conturbado de guerras e totalitarismos. Por exemplo, Bullet theory ou mass communication research conhecida como teoria da propaganda. $O$ uso de elementos como Estímulo, Resposta e Reforço, denota aproximação com a "psicologia behavorista" presente na Teoria Hipodérmica de Harold Lasswel de dimensão funcionalista. Outro 
exemplo é a Teoria Matemática da Informação que influenciou várias áreas do conhecimento, entre elas a Ciência da Informação. A Teoria Crítica e os Cultural Studies de grande influência política, social e cultural.

Compreendida aqui como uma teoria dos processos de comunicação, a Semiótica denominada como a Teoria dos Signos de Charles Sanders Peirce compreende a comunicação como uma atividade interpretativa dos signos (ADORNO, 1977; ESCOSTEGUY, 2001; FREITAG, 1994; MATELLART; MATELLART, 2011; PEIRCE, 1972; SANTAELLA, 2001; WOLF, 2006).

A comunicação para Rabaça e Barbosa (2001), é o "[...] conjunto de conhecimentos (linguísticos, psicológicos, antropológicos, sociológicos, filosóficos, cibernéticos, etc.,) relativos ao processo de comunicação [...]". Considera-se, pois, que essa dinâmica em sociedade (re)configura e gera novas leituras, aprendizados e representações.

Pinho (2006) afirma que o processo de comunicação interno visa que seus membros possam cumprir:

[...] suas tarefas estabelecidas. Pode ainda ser empregada com outros objetivos, como buscar a estabilidade da empresa, possibilitando assim, que ela atinja seus objetivos; conseguir a socialização dos seus membros; e criar e manter a cultura da organização (PINHO, 2006, p.105).

Ademais, subestimar a comunicação no contexto interno das indústrias é garantir o insucesso. Ao prescindir a comunicação da informação interna todo e qualquer tipo de organização condiciona-se ao fracasso. Aspectos como cultura, valores e objetivos comunicados nas rotinas internas promovem a harmonia dialógica na comunicação. Para Oliveira e Paula (2007) a comunicação interna permite trocas, estímulos, identificação de demandas frente aos problemas cotidianos. Pode ocorrer de duas formas segundo Pinho (2006), vertical ou horizontal. A primeira em ordem ascendente junto aos níveis hierárquicos de decisão 
e descendente que origina o feedback ao anterior. A segunda leva em conta a comunicação interna entre os demais níveis, setores, departamentos e agentes.

$\mathrm{Na}$ indústria, a comunicação visa aproximar as informações consideradas essenciais ao desempenho das atividades de qualquer sujeito, sobre processos específicos no contexto do fluxo interno da informação. O fluxo da informação é compreendido como parte integrante do processo de comunicação. É enquadrado desse modo, por explicar as fases que envolvem a dinâmica, percurso, etapas em que a informação é comunicada. Pode-se entendê-lo como um modelo explicativo do processo de comunicação frequentemente estudado por pesquisadores da Ciência da Informação.

A comunicação interna corresponde em ações objetivas para a promoção e a integração entre os vários níveis, setores, departamentos e colaboradores da indústria. Ademais, no escopo da análise do processo de comunicação permite-nos identificar os agentes que agem no processo interno de mediação da informação.

Para os fins desta seção, a definição de mediação é utilizada como pano de fundo para refletir sobre os agentes mediadores da informação no contexto interno da indústria. Do ponto de vista etimológico a mediação deriva do radical latino media. Designa uma ação que ocorre entre dois polos por decisão e intermediação de pessoas ou tecnologias. São recursos utilizados para resolução de problemas por um terceiro. Inúmeras indagações sobre o tema ilustram aspectos aplicados e compreensões distintas acerca da mediação, como: mediação de conflito, mediação social, mediação da informação, mediação cultural, dentre outras.

No âmbito da educação, deve promover a liberdade dos indivíduos no contexto sociocultural. Apropriar-se de uma dinâmica interativa entre mediador e mediado por ações de interferência e valorização de aspectos identitários, significando e re-significando a realidade (FREIRE, 1996; ROS, 2002). Para Coelho Netto (1997) e 
Davallon (2007) a mediação se insere no processo de comunicação da informação em proporcionar trocas e interações entre os agentes do processo. Silva e Ribeiro (2011) afirmam que a primeira mediação é a da língua. Almeida Júnior (2009) defende a mediação da informação enquanto uma ação articulada, não neutra de interferência explícita ou implícita com objetivo claro de aproximar a informação de quem dela precise por um agente mediador em qualquer espaço social.

As ações mediadoras da informação articulam organização, representação, sistematização e disseminação da informação. Pode resultar das experiências socioculturais também transmitidas pela oralidade (CUNHA; CAVALCANTI, 2008; GOMES, 2009). Ademais, se instala nas rotinas comunicativas das indústrias e dinamiza o acesso à informação.

As ações mediadoras se inserem na resolução de problemas de qualquer natureza pelos Agentes Mediadores ou gatekeepers. Para Allen (1979) os gatekeepers se tornam essenciais ao contexto interno das organizações, face a sua atuação na comunicação informal e na filtragem de informações. Nesse contexto, entende-se que o perfil característico do agente mediador na indústria pode ser um profissional da informação com formação específica ou as pessoas chave nas atividades internas. Deve ser valorizado e incentivado internamente por contribuir com a formação de redes internas de acesso à informação. As suas características pessoais como experiência e domínio técnico, confere ao agente mediador a liderança da equipe (KREMER, 1980). Segundo Meadows (1999, p. 146-148), o gatekeeper (pessoa-chave) "[deve ter acesso a uma variedade de fontes [...]". Suas atividades ficam próximas das necessidades e aspirações daqueles grupos ou indivíduos que precisam de sua interferência. Os atributos exigidos assemelham-se àqueles declarados na literatura da Ciência da Informação como necessários aos profissionais da informação.

Tais atributos são destacados na literatura quanto à formação e atuação do profissional da informação, a saber: ser comunicativo, 
mediador, motivador, ter capacidade analítica, flexibilidade, trabalhar em cooperação, formação continuada, elevado nível de conhecimento sobre o contexto de atuação, domínio das tecnologias, cuidado ético, conhecimento de gestão e compromisso social (GUIMARÃES, 1998; 2000; MARCHIORI, 1996; TARAPANOFF, 1997).

Incorpora-se nesse entendimento como agente mediador ou gatekeeper, profissionais da informação em ocupações consideradas tradicionais com formação acadêmica e aqueles com amplo conhecimento proporcionado pela experiência na indústria e por possuírem atributos dos quais se apresentam certa similaridade em suas práticas. Sendo assim, o agente mediador da informação em contextos especializados é um especialista do setor sucroalcooleiro. Desenvolve tarefas de busca e filtragem da informação sobre questões técnicas em ocorrências críticas nas rotinas internas da indústria sucroalcooleira.

\section{PERCURSO METODOLÓGICO}

A pesquisa de acordo com seu objetivo foi classificada como um estudo de caso (YIN, 2010). Os dados analisados fazem parte de pesquisa de mestrado defendida em 2013. Para este trabalho, buscouse aprofundar a análise a partir de interpretações dos processos no contexto abordado. A amostra da pesquisa foi extraída mediante um universo de aproximadamente 200 unidades industriais no Estado de São Paulo, esta amostragem foi definida como não-probabilística por tipicidade. Desse modo, permitiu a definição do critério para escolha de uma indústria, entre àquelas com alta produtividade de álcool em 2010 (ACKOFF, 1967; GIL, 2009; REA; PARKER, 2000). No período, a indústria escolhida ficou entre as 20 (vinte) maiores em produtividade do ranking de indústrias elaborado exclusivamente para esta pesquisa, a partir da compilação de dados de instituições do setor e de órgãos governamentais, federal e estadual. 
Os sujeitos da pesquisa foram encarregados, assistentes administrativos e técnicos dos Departamentos de Controle de Qualidade (CQ), Recursos Humanos (RH) e Segurança no Trabalho (ST). A indústria pesquisada está localizada na região administrativa de São José do Rio Preto, que em 2010 detinha a maior concentração de unidades industriais em produção de álcool. $\mathrm{Na}$ pesquisa foi determinada a entrevista, questionário e diário para coleta de dados. Neste trabalho, serão apresentados e analisados os resultados das entrevistas sob o olhar da Análise de Conteúdo.

No presente trabalho foi utilizado o método Análise de Conteúdo seguindo os passos propostos por Bardin (1977). A análise de conteúdo se coloca a serviço da compreensão das questões apresentadas, e visa à diminuição das incertezas por permitir leituras mais sofisticadas dos resultados obtidos (BARDIN, 1977). Os temas escolhidos foram abordados anteriormente no referencial teórico, a Comunicação interna e os Agentes mediadores.

A primeira fase foi constituída da pré-análise ou organização da análise, onde se realiza a leitura flutuante do material; escolha dos documentos para análise; formulação de hipóteses e objetivos; constituição de indicadores. Cabe ressaltar que para essa operação requereu atenção quanto aos seguintes princípios propostos por Bardin (1977): Exaustividade: todas as entrevistas realizadas na pesquisa compõem o corpus de análise, sendo oito entrevistas, a saber: três entrevistados do Departamento de Controle de Qualidade, três do Departamento de Segurança do Trabalho e dois do Departamento de Recursos Humanos; a representatividade é um princípio adotado neste trabalho, fato que toda entrevista analisada envolveu os departamentos estudados; Homogeneidade: as entrevistas tratam de todas as temáticas propostas e seguiu um roteiro semiestruturado; quanto ao princípio de pertinência, as escolhas metodológicas atenderam aos objetivos propostos à pesquisa. 
Marcio Ferreira da Silva

Processo de comunicação no ambiente interno de uma indústria:

compreensões a partir da análise de conteúdo

A segunda fase, exploração do material, consistiu em operações de decodificação do texto analisado. Considerou-se no processo a leitura e recorte de trechos das entrevistas e reunião de pontos semelhantes de acordo com a temática abordada. Nesse sentido, permitindo a criação das categorias e subcategorias. A terceira fase correspondeu à inferência, interpretação dos dados e apresentação e discussão dos resultados.

\subsection{Resultados e Análise}

As categorias resultantes das fases anteriores foram escolhidas a partir da literatura analisada e leituras das entrevistas. Ao citar os departamentos utilizamos as siglas já apresentadas no item anterior.

A análise buscou evidenciar algumas reflexões sobre os pontos de convergência identificados nas entrevistas de acordo com as variáveis, com ênfase na compreensão sobre o processo de comunicação ao lançar luz sobre as subcategorias.

Quadro 1 - Processo de comunicação dos três departamentos.

\begin{tabular}{|l|l|l|l|l|}
\hline CATEGORIA & \multicolumn{3}{|c|}{ COMUNICAÇÃo } \\
\hline \multirow{2}{*}{ Subcategorias } & Meios/canais & Causa de ruídos & $\begin{array}{c}\text { Motivação entre } \\
\text { setores/ } \\
\text { departamentos }\end{array}$ & \multicolumn{1}{|c|}{$\begin{array}{l}\text { Incidentes } \\
\text { críticos }\end{array}$} \\
\cline { 2 - 5 } & $\begin{array}{l}\text { Cartazes, } \\
\text { correio } \\
\text { eletrônico, } \\
\text { reuniões, } \\
\text { sinalizações } \\
\text { verticais e } \\
\text { horizontais, } \\
\text { jornalzinho, } \\
\text { faixas, rádios } \\
\text { comunicadore } \\
\text { s, imagens, } \\
\text { sinais } \\
\text { sonoros, } \\
\text { computador, } \\
\text { telefone } \\
\text { (móvel e fixo). }\end{array}$ & $\begin{array}{l}\text { Congestionament } \\
\text { o de rádios } \\
\text { comunicadores; } \\
\text { Setores } \\
\text { estratégicos sem } \\
\text { rádio - CQ; } \\
\text { Intranet lenta; } \\
\text { Restrição de uso } \\
\text { da Internet e } \\
\text { mídias. }\end{array}$ & $\begin{array}{l}\text { Reuniões cascata; } \\
\text { Alterações de normas; } \\
\text { Incidentes críticos; } \\
\text { Elaboração de } \\
\text { relatórios; } \\
\text { Situações de risco; } \\
\text { Integração de novas } \\
\text { equipes; } \\
\text { Indicadores, objetivos } \\
\text { e metas. } \\
\text { Incêndio do bagaço. }\end{array}$ & $\begin{array}{l}\text { Acionar o rádio; } \\
\text { Emitir sinal } \\
\text { sonoro da } \\
\text { caldeira; } \\
\text { Emissão de alerta } \\
\text { luminoso; } \\
\text { Reunião em } \\
\text { campo; } \\
\text { Registro em } \\
\text { diário; } \\
\text { Fotografia. }\end{array}$ \\
\hline
\end{tabular}

Fonte: Dados da pesquisa. 
Entre as entrevistas dos departamentos analisados, cabe destacar a variedade dos Meios/canais formais e informais presentes nas atividades de rotina do $\mathrm{CQ}, \mathrm{RH}$ e ST. Há relevante complexidade na atividade envolvida neste segmento, o que requer um mosaico de possibilidades e compreensões acerca de uma tipologia de meios e canais necessários ao processo de comunicação tão específico. Deve permitir trocas e interações constantes de elementos no processo de comunicação definido por Rabaça e Barbosa (2001). O CQ revelou não possuir um rádio comunicador próprio. No entanto, utiliza rádios emprestados do Departamento de Segurança do Trabalho.

As sinalizações verticais e horizontais e as imagens estão presentes em toda a indústria. Geralmente, comunicam informações previamente estabelecidas por normas e são disseminadas em reuniões de integração de novas equipes e boletins, por exemplo: informam rotas de fuga, circulação ou uso obrigatório de determinados equipamentos de proteção individual, e, além disso, disciplinam procedimentos em ocasiões específicas como incidentes críticos.

As causas de ruídos ou impedimentos mais comuns identificados nas entrevistas: intranet e internet, estas revelam problemas de ordem estrutural, como lentidão de acesso e restrições de uso. Ademais, os congestionamentos na comunicação entre os rádios comunicadores e impedimentos na utilização de mídias nas rotinas internas, são apresentados como um constante problema identificado nas entrevistas dos três departamentos estudados. Por se tratar de um segmento muito competitivo da indústria brasileira, esse comportamento revela alto grau de controle sobre processos que envolvem a informação interna. Além disso, essa prática influencia na fluidez do fluxo da informação interna e interrupções em parte do processo de comunicação interna.

As motivações frequentes desencadeiam vários processos na comunicação entre os departamentos pesquisados, setores e instancias de poder de decisão mais elevada. Nota-se, conforme destacou Pinho (2006), que a comunicação ocorre continuamente em cascata e entre 
vários níveis e setores, vertical ou horizontal. Após a leitura flutuante e de uma exploração mais aguda das entrevistas, foi possível identificar, além das motivações destacadas no Quadro 1, a urgência por registros de cada atividade motivadora como: elaboração de relatórios, indicadores, treinamentos de novas equipes com foco em incidentes críticos. Tais procedimentos são habitualmente realizados pelos entrevistados dos departamentos em formulários específicos (eletrônicos e impressos) e em diários. Envolve situações de risco, incidentes e responde as questões de metas da indústria. Essa troca constante identifica as demandas internas e os problemas no cotidiano (OLIVEIRA; PAULA, 2007).

Em incidentes críticos a utilização da sirene ou alarme sonoro similar, é considerada vital ao sucesso das atividades relacionadas aos procedimentos de segurança, segundo o ST. Um dos entrevistados enfatizou a importância desses meios nas rotinas da indústria para indicar procedimentos de parada da linha de produção ou alerta de perigo. Símbolos convencionais que comunicam com frequência ações padronizadas e estabelecidas por convenções normativas provenientes da empresa ou adotadas por normas ISO, por exemplo. Ademais, do ponto de vista de um olhar da semiótica - tipos de símbolos em sinalizações verticais ou horizontais, cores, iluminação específica em setores - revelam a complexidade do processo de comunicação interna. A função do signo é representar algo sem necessariamente ser essa coisa representada (PEIRCE, 1972; SANTAELLA, 2001). A interpretação dependerá da experiência dos envolvidos com os códigos internos estabelecidos na indústria. Diante dessas perspectivas, entende-se o processo de comunicação da informação com atividade interpretativa. Foca na transferência da informação no contexto da indústria influenciado por aspectos socioculturais, políticos, econômicos e tecnológicos. 
A participação dos agentes mediadores no processo de comunicação da informação é analisada com foco na categoria Agente e de subcategorias extraídas do corpus analisado.

Quadro 2 - Participação dos Agentes mediadores no processo de comunicação.

\begin{tabular}{|c|c|c|c|c|}
\hline \multirow[t]{2}{*}{ CATEGORIA } & \multicolumn{4}{|c|}{ AGENTE } \\
\hline & $\begin{array}{l}\text { Obstáculo ao } \\
\text { acesso }\end{array}$ & $\begin{array}{l}\text { Situações } \\
\text { complexas }\end{array}$ & $\begin{array}{l}\text { Auxílio dos } \\
\text { agentes }\end{array}$ & Atributos \\
\hline Subcategorias & $\begin{array}{l}\text { Baixa atualização } \\
\text { do banco de } \\
\text { dados; } \\
\text { Informação } \\
\text { incompleta; } \\
\text { Bloqueio do } \\
\text { sistema; } \\
\text { Internet lenta ou } \\
\text { restrita; } \\
\text { Funcionário } \\
\text { antigo retém } \\
\text { informações. }\end{array}$ & $\begin{array}{l}\text { Resultados de } \\
\text { análises do } \\
\text { laboratório; } \\
\text { Qualidade do } \\
\text { produto; } \\
\text { Manifesto de } \\
\text { clientes; } \\
\text { Busca de } \\
\text { históricos; } \\
\text { Risco de acidente. } \\
\text { Processos de } \\
\text { produção. }\end{array}$ & $\begin{array}{l}\text { Coordenador de } \\
\text { produção; } \\
\text { Encarregado; } \\
\text { Líder; Supervisor; } \\
\text { Operador; } \\
\text { Gerente } \\
\text { industrial; } \\
\text { Técnicos; } \\
\text { Consultores } \\
\text { terceirizados; } \\
\text { Fornecedores. }\end{array}$ & $\begin{array}{l}\text { Especialistas; } \\
\text { Experiência no } \\
\text { ramo de } \\
\text { atividade; } \\
\text { Conhecimento } \\
\text { técnico; } \\
\text { Muito tempo de } \\
\text { empresa; } \\
\text { Liderança. }\end{array}$ \\
\hline
\end{tabular}

Fonte: Dados da pesquisa.

Considerou-se a presença dessas subcategorias na participação dos agentes mediadores, o pressuposto basilar à questão levantada nesse aspecto, visou entender sobre os obstáculos ao acesso à informação identificados nas rotinas pelas entrevistas. Para todos os departamentos a ausência de atualizações do banco de dados da empresa figura como um dos problemas no repasse de informações pelos agentes na mediação da informação. A retenção de informações sobre processos por parte dos funcionários com mais tempo de empresa apresentam informações incompletas. Desse modo, sugere mais cuidado com as informações disponibilizadas como afirmam Allen (1979) e Meadows (1999) sobre as características da pessoa-chave: aproximar e filtrar a informação.

As constatações revelam alguns precedentes preocupantes para organizações como a estudada neste trabalho. Em situações complexas as informações incorporam-se às questões relacionadas aos processos e a qualidade dos produtos. Os agentes também auxiliam em 
comunicações de informações envoltas sobre situações de risco e busca por históricos em registros presentes nos departamentos.

Cada departamento possui um diário responsável pelo histórico de suas atividades. A produção desses registros envolve os agentes mediadores ou gatekeepers. Notadamente, essas mediações podem sofrer interferências, principalmente, em comunicações informais nos setores da indústria. A neutralidade na mediação de informações no processo de comunicação não se configura em algo possível. A mediação desvela-se como uma prática conjugada por contextos culturais, políticos e econômicos (ALMEIDA JÚNIOR, 2009; CUNHA; CAVALCANTI, 2008). Nesse sentido, o agente deve levar em conta os objetivos, metas, cultura da indústria.

Nas situações, identificadas no corpus analisado, os agentes auxiliam frequentemente com informações nas comunicações entre os departamentos e setores. Atribuíram destaque para os coordenadores envolvidos com processo de produção, encarregados e líderes dos setores, supervisores, operadores, gerentes, técnicos, consultores externos e fornecedores.

As escolhas desses agentes ocorrem pela identificação de características denominadas nas subcategorias de atributos. Esses gatekeepers são especialistas nas atividades que desempenham, as informações oferecidas estão diretamente vinculadas aos espaços de sua atuação. Os atributos como experiência no ramo de atividade no setor sucroalcooleiro por longo tempo, a formação técnica formal somada a atividade e tempo de empresa e a liderança reconhecidamente exercida nos ambientes internos, são razões que creditam a esses agentes o elevado nível de produtividade no canavial que incide sobre os demais processos de produção. Sobretudo, elevando a produtividade álcool na indústria e a mesma ao patamar dentre as maiores da América Latina. 


\section{CONSIDERAÇÕES FINAIS}

A presente pesquisa investigou os processos de comunicação interna em uma indústria de alta produtividade do setor sucroalcooleiro do estado de São Paulo. A partir da análise das entrevistas realizadas em três departamentos: Controle de Qualidade, Recursos Humanos e Segurança do Trabalho; vitais ao funcionamento da indústria. Foi possível compreender como os agentes visualizam o processo e identificam a sua efetiva participação no mesmo.

Tomando a Análise de Conteúdo proporcionou inferir nas mensagens a presença das variáveis propostas pelas subcategorias. Nesse sentido, conseguiu impor um rigor e uma linha de raciocínio acerca do processo ora estudado.

Quanto aos processos de comunicação conseguiu identificar alguns problemas relacionados aos ruídos e aos meios utilizados pelos agentes. No entanto, foi possível detalhar parte das motivações internas que permeiam as atividades relacionadas à comunicação interna. Em organizações como a indústria sucroalcooleira, amplamente competitiva, é essencial ao seu adequado funcionamento. Compreender os processos de comunicação configura-se numa tarefa complexa que envolve muitas variáveis, evidenciadas nesta pesquisa mediante os dados e análises apresentados.

Contudo, a análise dos dados sugere algumas considerações de suma importância à indústria sobre os processos de comunicação e aos agentes mediadores da informação. Em primeiro lugar, há necessidade de refletir sobre as barreiras de acesso e ruídos identificados na análise. Em segundo, a intensa interação entre departamentos e setores de vários níveis de decisão configura um espaço de efetiva ação dos gatekeepers. E por fim, para mediar informações deve-se analisar as consequências da manutenção dessas barreiras no cotidiano da indústria e a potencial interferência no desempenho das atividades. 


\section{REFERÊNCIAS}

ACKOFF, Russel L. Planejamento de pesquisa social. São Paulo: Herder, 1967.

ADORNO, Theodor W. A indústria cultural. In: COHN, Gabriel. (Org.). Comunicação e indústria cultural: leituras de análise dos meios de comunicação na sociedade contemporânea e das manifestações da opinião pública, propaganda e "cultura de massa" nessa sociedade. 5. ed. São Paulo: Nacional, 1977. p. 287-295.

ALLEN, Thomas J. Managing the flow of technology: technology transfer and the dissemination of technological information within the R\&D organization. Cambridge: MIT Press, 1979. p. 141-181.

ALMEIDA JÚNIOR, Oswaldo. F. Mediação da informação e múltiplas linguagens. Tendências na Pesquisa Brasileira em Ciência da Informação, Brasília, v. 2, n. 1, p. 89-103, jan./dez. 2009.

BARDIN, Laurence. Análise de conteúdo. Lisboa: Edições 70, 1977.

BRAY, Sílvio Carlos; FERREIRA, Enéias Rente; RUAS, Davi Guilherme Gaspar. As políticas da agroindústria canavieira e o Proálcool no Brasil. Marília: Unesp Marília Publicações, 2000.

COELHO NETTO, Teixeira. Dicionário crítico de políticas culturais: cultura e imaginário. São Paulo: FAPESP: Iluminuras, 1997.

CUNHA, Murilo Bastos; CAVALCANTI, Cordélia Robalinho de Oliveira. Dicionário de biblioteconomia e arquivologia. Brasília: Briquet de Lemos, 2008.

ROS, Silvia Zanata da. Pedagogia e mediação em Reuven

Feuerstein: o processo de mudança em adultos com história de deficiência. São Paulo: Plexus, 2002.

DAVALLON, Jean. A mediação: a comunicação como processo?

Prisma, Porto, n. 4, 2007.

EJARQUE, Luis García. Diccionario del archivero bibliotecario: terminología de la elaboración, tratamiento y utilización de los materiales propios de los centros documentales. Espanha: Trea, 2000.

ESCOSTEGUY, Ana Carolina. Os estudos culturais. In: HOLFELDT, Antonio; MARTINO, Luiz C.; FRANÇA, Vera Veiga. (Org.). Teorias da comunicação: conceitos, escolas e tendências. Petrópolis: Vozes, 2001. p.151-170. 
FURTADO, Celso. Formação econômica do Brasil. 32. ed. São Paulo: Companhia Editora Nacional, 2005.

FREITAG, Barbara. A teoria crítica: ontem e hoje. 5. ed. São Paulo: Brasiliense, 1994.

FREIRE, Paulo. Pedagogia da autonomia: saberes necessários à prática educativa. 39. ed. São Paulo: Paz e Terra, 1996.

GIL, Antonio Carlos. Métodos e técnicas de pesquisa social. 6. ed. São Paulo: Atlas, 2009.

GOMES, Henriette Ferreira. A mediação da informação, comunicação e educação na construção do conhecimento. DataGramaZero, Rio de Janeiro, v. 9, n. 1, jan. 2009.

GUIMARÃES, José Augusto Chaves. Moderno profissional da informação: a formação, o mercado e o exercício profissional no Brasil. CBF: Informa, Brasília, v. 3, n. 2, p. 6-7, abr. 1998.

GUIMARÃES, José Augusto Chaves. O profissional da informação sob o prisma de sua formação. In: VALENTIM, M. L. P. (Org.). Profissionais da informação: formação, perfil e atuação profissional. São Paulo: Polis, 2000. p. 53-70.

KREMER, Jeannette. Information flow among engineers in a design company. 1980. $158 \mathrm{f}$. Thesis (Doctor of Philosophy in Library Science) - School of Library Science, University of Illinois, Urbana, 1980.

MAIA, Patrícia Albano. Expansão territorial do Brasil colonial: o bandeirismo. In: ODÁLIA, Nilo; CALDEIRA, João Ricardo de Castro (Org.). História do Estado de São Paulo: a formação da unidade paulista: São Paulo Colônia e Império. São Paulo: Ed. UNESP; Arquivo Público do Estado: Imprensa oficial, 2010. v. 1, p. 93-103.

MARCHIORI, Patrícia. Zeni. Que profissional queremos formar para o século XXI: graduação. Informação \& Informação, Londrina, v. 1, n. 1 , p. 27-34, jan./jun. 1996.

MATELLART, Armand; MATELLART, Michèle. Histórias das teorias da comunicação. 14. ed. São Paulo: Loyola, 2011.

MEADOWS, Arthur Jack. A comunicação científica. Brasília: Briquet de Lemos, 1999.

OLIVEIRA, Ivone de Lourdes; PAULA, Maria Aparecida. O que é comunicação estratégica nas organizações. São Paulo: Paulus, 2007. 
PEIRCE, Charles Sanders. Semiótica e filosofia. São Paulo: Cultrix, 1972.

PETRONE, Maria Thereza Schorer. A lavoura canavieira em São Paulo: expansão e declínio (1765-1851). São Paulo: Difusão Européia do Livro, 1968.

PINHO, Jose Benedito. Comunicação nas organizações. Viçosa: Ed. UFV, 2006.

RABAÇA, Carlos Alberto; BARBOSA, Gustavo Guimarães. Dicionário de comunicação. 2. ed. Rio de Janeiro: Campus, 2001.

REA, Louis M.; PARKER, Richard A. Metodologia de pesquisa: do planejamento à execução. São Paulo: Pioneira, 2000. p. 123-151.

SANTAELLA, Lucia. Matrizes da linguagem e pensamento: sonora, visual, verbal: Aplicações na hipermídia. São Paulo: lluminuras: Fapesp, 2001.

SARACEVIC, Tefko. Information Science. Journal of The American Society for Information Science, New York, v. 50, n. 12, p. 1051-1063, 1999.

MARTÍNEZ DE SOUSA, José. Diccionario de bibliología y ciencias afines. 3. ed. Gijón: Trea, 2004.

SILVA, Armando Malheiro da; RIBEIRO, Fernanda. Paradigmas serviço e mediações na Ciência da Informação. Recife: Néctar, 2011.

SMIT, Johanna W.; BARRETO, Aldo de Albuquerque. Ciência da informação: base conceitual para a formação profissional. In:

VALENTIN, Marta Ligia Pomim (Org.). Formação do profissional da informação. São Paulo: Polis, 2002. Cap. 1, p. 9-24.

TARAPANOFF, Kira. Perfil do profissional da informação no Brasil. Brasília: FIBRA/IEL, 1997.

WOLF, Mauro. Teorias da comunicação. 8. ed. São Paulo: Presença, 2006.

YIN, Robert. K. Estudo de caso: planejamento e métodos. 4. ed. Porto Alegre: Bookman, 2010.

\section{Title}

Indoor communication process in an industry: comprehension from content analysis 


\begin{abstract}
Introduction: This paper discusses and analyzes the communication process in an industry of the sugarcane sector in the state of São Paulo. It aims to identify the understanding and participation of mediating agents of information in the communication process.

Methodology: The research is presented as a case study. The analyzed corpus was composed by eight interviews conducted in 2013 in one of the 20 largest industries producing alcohol in 2010 in São Paulo. The analysis of the interviews was employed content analysis.

Results: There was some noises and problems regarding the use of means in the process. The participation of agents is identified as essential to the flow of information and formal and informal communication of the internal environment of the industry.

Conclusions: Nevertheless, it is suggested a more effective look at the noises and information access barriers and their consequences to the industry. Finally, it recognizes the action of mediating agents or gatekeepers of information among respondents of the analyzed departments.
\end{abstract}

Keywords: Communication of information. Mediating agents. Sugarcane industry - São Paulo. Content analysis.

\title{
Titulo
}

Proceso de comunicación en el ambiente interno de una industria: comprensiones a partir del análisis de contenido

\section{Resumen}

Introducción: El presente trabajo discute y analiza el proceso de comunicación en una industria del sector sucroalcoholero del estado de São Paulo. Visa identificar la comprensión y la participación de los agentes mediadores de la información en el proceso de comunicación.

Metodología: La pesquisa se presenta como un estudio de caso. El corpus analizado fue compuesto por ocho entrevistas realizadas en 2013, en una de las 20 mayores industrias productoras de etanol en 2010 en el estado de São Paulo. En cuanto al análisis de las entrevistas fue utilizado el Análisis de Contenido.

Resultados: Se verificó algunos ruidos y problemas en relación al uso de medios en el proceso. La participación de los agentes es identificada como fundamental al flujo de información y comunicación formal e informal del ambiente interno de la industria.

Conclusiones: Sin embargo, sugiere una mirada más efectiva sobre los ruidos y las barreras de acceso a la información y sus consequências a la industria. Por fin, se reconoce la acción de los agentes mediadores de la información o gatekeepers entre los encuestados de los departamentos analizados.

Palabras clave: Comunicación de la información. Agentes mediadores. Industria sucroalcoholera - São Paulo. Análisis de contenido.

Recebido: 02.12.2014

Aceito: 19.02 .2016

Inf. Inf., Londrina, v. 21, n. 1, p. $306-323$, jan./abr. 2016. 